\title{
IDENTIFIKASI KAPASITAS RUAS JALAN LETJEN IBRAHIM ADJIE STA. $3+100$ DI PERLINTASAN SEBIDANG KERETA API KOTA TASIKMALAYA
}

\author{
Dany Hamdani ${ }^{1}$ An An Anisarida ${ }^{2}$ \\ ${ }^{1}$ Teknik Sipil Universitas Winaya Mukti \\ Email: hamdanidany19@gmail.com; anananisarida@gmail.com
}

\begin{abstract}
Transportation is an important thing and cannot be separated from human life. Good transportation is smooth, convenient and efficient transportation. On Jalan Letjen Ibrahim Adjie in Tasikmalaya City, there is a grade crossing with the railroad tracks. This study aims to find and measure the capacity of Jalan Letjen Ibrahim Adjie section at the grade crossing of Tasikmalaya City. Primary data used are the results of geometric measurements of Roads and data collection on the capacity of Jalan Letjen Ibrahim Adjie. Whereas secondary data was obtained from related institutions. From the analysis it can be seen that the ratio of current to capacity of Jalan Letjen Ibrahim Adjie in 2019 $(V / C)$ at 0.319 , identified as smooth transportation. The degree of saturation of the volume per capacity $(V / C)$ ratio will become saturated at 0.795 , predicted to occur in 2034 with the assumption of 6\% traffic growth per year and road capacity is still the same as in 2019. It is necessary to do an alternative handling of the traffic jam, namely the construction of elevated road junction, such as fly over or under pass.
\end{abstract}

Keywords: Road capacity, geometric, grade crossing.

\begin{abstract}
ABSTRAK
Transportasi merupakan suatu hal yang penting dan tidak dapat dipisahkan dengan kehidupan manusia. Transportasi yang baik adalah transportasi yang lancar, nyaman, dan efisien. Pada Jalan Letjen Ibrahim Adjie di Kota Tasikmalaya terdapat perlintasan sebidang jalan dengan jalan rel kereta api. Penyusunan ini bertujuan untuk mencari dan mengukur kapasitas ruas Jalan Letjen Ibrahim Adjie di perlintasan sebidang Kota Tasikmalaya. Data yang digunakan adalah data primer yang meliputi hasil pengukuran geometrik Jalan dan pendataan kapasitas ruas Jalan Letjen Ibrahim Adjie. Sedangkan data sekunder diperoleh dari institusi yang terkait. Dari hasil analisis terlihat bahwa rasio arus terhadap kapasitas ruas Jalan Letjen Ibrahim Adjie pada tahun 2019 (V/C) sebesar 0,319 teridendifikasi lancar. Dengan angka pertumbuhan kendaraan rata-rata dari 2016 sampai dengan 2018 sebesar 7.3\% per tahun di kota Tasikmalaya, maka untuk rasio arus jalan Letjen Ibahim Adjie tahun 2020 dengan asumsi kapasitas sama dengan tahun 2019, (V/C) adalah 0,343 teridendifikasi lancar. Prediksi akan jenuh atau macet (V/C) sebesar 0,795 terjadi pada tahun 2034 dengan asumsi pertumbuhan lalu lintas 6\% per tahun dan kapasitas jalan masih sama dengan tahun 2019, maka perlu dilakukan alternatif penanganan kemacetan yaitu dengan dibangunnya perlintasan tak sebidang, seperti fly over atau under pass.
\end{abstract}

Kata kunci: kapasitas jalan, geometrik jalan, perlintasan sebidang.

\section{PENDAHULUAN}

Latar Belakang

Transportasi yang baik adalah transportasi yang lancar, nyaman, dan efisien. Demi terwujudnya transportasi darat yang baik diperlukan infrastruktur yang memadai, dalam hal ini adalah jalan raya. Menurut Undang-Undang Republik 
Indonesia No 38 Tahun 2004 Tentang jalan, pengertian jalan adalah prasarana transportasi darat yang meliputi segala bagian jalan, termasuk bangunan pelengkap dan perlengkapannya yang diperuntukkan bagi lalu lintas, yang berada pada permukaan tanah, di atas permukaan tanah, di bawah permukaan tanah dan atau air, serta di atas permukaan air, kecuali jalan kereta api, jalan lori, dan jalan kabel.Permasalahan lalu lintas sering terjadi di daerah Kota Tasikmalaya, terutama lalu lintas yang berada pada ruas jalan antar kota antar provinsi, atau jalan dengan status jalan Nasional. Permasalahan ini ditimbulkan oleh banyaknya kendaraan yang melintasi ruas jalan tersebut yang didominasi oleh kendaraan berdimensi besar seperti truk dan bus, serta terdapat beberapa perlintasan sebidang jalan dengan rel kereta api. Ruas Jalan Letjen Ibrahim Adjie merupakan salah satu ruas jalan di Kota Tasikmalaya berstatus jalan Nasional dengan tipe jalan 2 lajur 2 arah. Ruas jalan ini sering mengalami permasalahan lalu lintas, yang mana terjadi penumpukan kendaraan di sekitar perlintasan sebidang dengan rel kereta api. Akibat adanya perlintasan sebidang, kendaraan yang melintasi Jalan Letjen Ibrahim Adjie harus mengurangi kecepatan sehingga berdampak pada perubahan kapasitas ruas jalan tersebut. Keadaan ini mengakibatkan proses aktifitas lalu lintas menjadi terhambat yang berdampak pada telatnya perpindahan kendaraan sehingga waktu dan bahan bakar yang dibutuhkan bertambah.

\section{Rumusan Masalah}

Pada ruas Jalan Letjen Ibrahim Adjie Kota Tasikmalaya terdapat perlintasan sebidang jalan dengan rel kereta api, yang mempengaruhi kapasitas ruas jalan. Perubahan yang terjadi pada volume kendaraan akibat adanya perlintasan kereta api dengan jalan, serta saat penutupan palang pintu rel kereta api melintas berdampak kepada antrian kendaraan yang terjadi pada ruas Jalan Letjen Ibrahim Adjie Kota Tasikmalaya. Karena itu perlu dilakukan studi kasus untuk mengetahui seberapa besar volume kendaraan yang melintasi perlintasan sebidang ini.

\section{Maksud dan Tujuan}

Maksud penyusunan tugas akhir ini untuk mengetahui kapasitas ruas Jalan Letjen Ibrahim Adjie pada perlintasan sebidang Jalan Kereta Api Kota Tasikmalaya. Adapun tujuan penyusunan tugas akhir ini yaitu untuk mengukur penampang melintang jalan dan menghitung kapasitas ruas Jalan Letjen Ibrahim Adjie pada perlintasan sebidang Kota Tasikmalaya.

\section{Pembatasan Masalah}

Pembatasan masalah dalam studi kasus ini adalah sebagai berikut:

1. Pengamatan hanya dilakukan di perlintasan sebidang ruas Jalan Letjen Ibrahim Adjie di Kota Tasikmalaya, tepatnya di Station 3+100.

2. Pengukuran yang dibahas ialah volume lalu lintas terutama pada saat jam sibuk.

\section{Manfaat Studi Kasus}

Melalui studi kasus ini diharapkan memberikan manfaat berupa informasi tentang:

1. Volume kendaraan pada saat akan melewati perlintasan sebidang Jalan Letjen Ibrahim Adji dengan Jalan Kereta Api. 
2. Kapasitas ruas Jalan Letjen Ibrahim Adjie Kota Tasikmalaya yang terdapat perlintasan sebidang di station $3+100$.

3. Alternatif penanganan kemacetan yang terjadi di perlintasan sebidang station 3+100 ruas Jalan Letjen Ibrahim Adjie Kota Tasikmalaya.

\section{TINJAUAN PUSTAKA}

Karakteristik lalu lintas adalah arus kendaraan yang bergerak secara individual atau berkelompok pada suatu jalan atau jalur, yang dipengaruhi oleh perilaku manusia dan dinamika kendaraan. Ukuran kuantitatif dalam menilai karakteristik lalu lintas biasa dinyatakan dalam besaran aspek. Berdasarkan Manual Kapasitas Jalan Indonesia (1997), arus lalu lintas adalah jumlah unsur lalu lintas yang melalui titik tak terganggu di hulu, pendekat per satuan waktu (contoh : kebutuhan lalu lintas kend/jam, smp/jam).

Didalam MKJI tersebut nilai arus alu lintas (Q) mencerminkan komposisi lalu lintas, dengan menyatakan arus dalam satuan mobil penumpang (smp) dengan menggunakan ekivalen mobil penumpang (emp) yang diturunkan secara empiris untuk tipe kendaraan berikut:

1. Kendaraan ringan atau light vehicle (LV) termasuk mobil penumpang, minibus, pick up, truk kecil dan jeep.

2. Kendaraan berat atau heavy vehicle (HV) termasuk truk dan bus.

3. Sepeda motor atau motorcycle (MC).

\section{Volume Lalu Lintas}

Sebagai pengukur jumlah dari arus lalu lintas digunakan "volume". Volume lalu lintas menunjukan jumlah kendaraaan yang lewat pada satu titik pengamatan atau ruas jalan dalam satu satuan waktu pada setiap periode yang dipilih (hari, jam, menit). Volume lalu lintas harian rencana (VLHR) adalah prakiraan volume lalu lintas harian pada akhir tahun rencana lalu lintas dinyatakan dalam SMP/hari.

1. Satuan mobil penumpang (smp)

Satuan mobil penumpang (smp) adalah satuan kendaraan dalam hal kapasitas jalan, dimana satu mobil penumpang ditetapkan memiliki satu smp.

2. Ekivalensi mobil penumpang (emp)

Faktor konversi berbagai jenis kendaraan dibandingkan dengan mobil penumpang atau kendaraan ringan lainnya sehubungan dengan dampakya pada perilaku lalu lintas (untuk mobil penumpang dan kendaraan ringan lainnya, emp = 1.0). Emp untuk jenis-jenis kendaraan dan kondisi medan lainnya dapat dilihat dalam tabel 2.1 dibawah ini :

Tabel 2.1: Nilai Emp untuk Jenis-Jenis Kendaraan

\begin{tabular}{|c|l|c|}
\hline No & \multicolumn{1}{|c|}{ Tipe Kendaraan } & Nilai emp \\
\hline 1 & Sedan, Jeep, Station Wagon & 1,0 \\
\hline 2 & Pick-up, Bus Kecil, Truck Kecil & $1,2-3,5$ \\
\hline 3 & Bus dan Truck Besar & $1,2-6,0$ \\
\hline
\end{tabular}

Sumber : MKJI tahun 1997 tentang Jalan Perkotaan 
Menurut Manual Kapasitas Jalan Indonesia tentang Jalan Perkotaan (1997:518) Kapasitas jalan adalah jumlah kendaraan maksimum yang dapat melewati suatu jalan pada jalur jalan selama satu jam dengan kondisi serta arus lalu lintas tertentu. Untuk jalan dua - lajur dua - arah, kapasitas ditentukan untuk arus dua arah (kombinasi dua arah), tetapi untuk jalan dengan banyak lajur, arus dipisahkan per arah dan kapasitas ditentukan per lajur.

Persamaan dasar untuk menentukan kapasitas suatu ruas jalan perkotaan (Jalan Perkotaan, MKJI 1997:5-18) adalah sebagai berikut:

dimana :

$$
\mathrm{C}=\mathrm{Co} \times \mathrm{FCw} \times \mathrm{FCsp} \times \mathrm{FCsf} \times \mathrm{FCcs}
$$

$\mathrm{C} \quad=$ Kapasitas ruas jalan ( $\mathrm{smp} / \mathrm{jam})$

Co = Kapasitas dasar ( $\mathrm{smp} / \mathrm{jam})$

$\mathrm{FCw}=$ Faktor penyesuaian lebar jalur lalu lintas

FCsp $=$ Faktor penyesuaian pemisahan arah

FCsf $=$ Faktor penyesuaian hambatan samping

$\mathrm{FCcs}=$ Faktor penyesuaian ukuran kota

Jika kondisi sesungguhnya sama dengan kondisi dasar (ideal) yang ditentukan pada karakteristik geometrik, maka semua faktor penyesuaian menjadi 1,0 dan kapasitas menjadi sama dengan kapasitas dasar. Menurut Manual Kapasitas Jalan Indonesia tentang Jalan Perkotaan (1997:5-11), kapasitas dasar (Co) adalah kapasitas segmen jalan pada kondisi geometri, pola arus lalu lintas, dan faktor ligkungan yang ditentukan sebelumnya (ideal). Penentu kapasitas dasar (Co) jalan ditentukan berdasarkan tipe jalan dan jumlah jalur, terbagi atau tidak terbagi, seperti dalam Tabel 2.2

Tabel 2.2: Kapasitas Dasar (Co)

\begin{tabular}{llcc}
\hline No & \multicolumn{1}{c}{ Tipe jalan } & $\begin{array}{c}\text { Kapasitas dasar } \\
(\text { smp/jam })\end{array}$ & Keterangan \\
\hline 1 & Empat lajur terbagi & 1650 & Per lajur \\
\hline 2 & Empat lajur tidak terbagi (4/2 UD) & 1500 & Per lajur \\
\hline 3 & Dua lajur tidak terbagi (2/2 UD) & 2900 & Total untuk dua arah \\
\hline
\end{tabular}

Sumber: Jalan Perkotaan, MKJI 1997;5-50

Tabel 2.3: Penyesuaian Kapasitas untuk Pemisahan Arah (FCsp)

\begin{tabular}{|c|c|c|c|c|c|c|}
\hline 1 & Pemisahan arah SP \% - \% & $50-50$ & $55-45$ & $60-40$ & $65-35$ & $70-30$ \\
\hline \multirow[t]{2}{*}{2} & Dua-lajur & 1,00 & 0,97 & 0,94 & 0,91 & 0,88 \\
\hline & Empat-laju & 1,00 & 0,985 & 0,97 & 0,955 & 0,94 \\
\hline 3 & $\begin{array}{l}\text { Dua lajur tidak terbagi }(2 / 2 \\
\text { UD) }\end{array}$ & 2900 & $\begin{array}{c}\text { Total untuk } \\
\text { dua arah }\end{array}$ & & & \\
\hline
\end{tabular}

Sumber: Jalan Perkotaan, MKJI 1997;5-52 
Tabel 2.4: Penyesuaian Kapasitas untuk Pengaruh Lebar Jalur Lalu Lintas untuk Jalan Perkotaan (FCw)

\begin{tabular}{|c|c|c|c|}
\hline \multirow[b]{2}{*}{ No } & \multicolumn{3}{|c|}{ Lebar jalur lalu } \\
\hline & Tipe Jalan & $\begin{array}{l}\text { lintas efektif }(\mathrm{Wc}) \\
(\mathrm{m})\end{array}$ & $\mathrm{FCw}$ \\
\hline \multirow[t]{6}{*}{1} & Empat lajur terbagi atau jalan satu arah & Per lajur & \\
\hline & & 3,00 & 0,92 \\
\hline & & 3,25 & 0,96 \\
\hline & & 3,50 & 1,00 \\
\hline & & 3,75 & 1,04 \\
\hline & & 4,00 & 1,08 \\
\hline \multirow[t]{6}{*}{2} & Empat lajur tidak terbagi & Per lajur & Perlajur \\
\hline & & 3,00 & 0,91 \\
\hline & & 3,25 & 0,95 \\
\hline & & 3,50 & 1,00 \\
\hline & & 3,75 & 1,05 \\
\hline & & 4,00 & 1,09 \\
\hline \multirow[t]{8}{*}{3} & Dua lajur tidak terbagi & Total dua arah & \\
\hline & & 5 & 0,56 \\
\hline & & 6 & 0,87 \\
\hline & & 7 & 1,00 \\
\hline & & 8 & 1,14 \\
\hline & & 9 & 1,25 \\
\hline & & 10 & 1,29 \\
\hline & & 11 & 1,34 \\
\hline
\end{tabular}

Sumber: Jalan Perkotaan, MKJI 1997;5-51

Tabel 2.5: Penyesuaian Kapasitas untuk Hambatan Samping (FCsf) berdasarkan Lebar Bahu Efektif Ws

\begin{tabular}{|c|c|c|c|c|c|c|}
\hline \multirow{3}{*}{ No } & \multirow{3}{*}{ Tipe Jalan } & \multirow{3}{*}{$\begin{array}{c}\text { Kelas } \\
\text { hambatan } \\
\text { samping }\end{array}$} & \multirow{2}{*}{\multicolumn{4}{|c|}{$\begin{array}{l}\text { Faktor penyesuaian untuk hambatan samping dan lebar } \\
\text { bahuFCsf }\end{array}$}} \\
\hline & & & & & & \\
\hline & & & $\leq 0,5$ & 1,0 & 1,5 & $\geq 2,0$ \\
\hline \multirow[t]{5}{*}{1} & $4 / 2 \mathrm{D}$ & $\mathrm{VL}$ & 0,96 & 0,98 & 1,01 & 1,03 \\
\hline & & $\mathrm{L}$ & 0,94 & 0,97 & 1,00 & 1,02 \\
\hline & & M & 0,92 & 0,95 & 0,98 & 1,00 \\
\hline & & $\mathrm{H}$ & 0,88 & 0,92 & 0,95 & 0,98 \\
\hline & & $\mathrm{VH}$ & 0,84 & 0,88 & 0,92 & 0,96 \\
\hline \multirow[t]{5}{*}{2} & $4 / 2$ UD & $\mathrm{VL}$ & 0,96 & 0,99 & 1,01 & 1,03 \\
\hline & & $\mathrm{L}$ & 0,94 & 0,97 & 1,00 & 1,02 \\
\hline & & M & 0,92 & 0,95 & 0,98 & 1,00 \\
\hline & & $\mathrm{H}$ & 0,87 & 0,91 & 0,94 & 0,98 \\
\hline & & $\mathrm{VH}$ & 0,80 & 0,86 & 0,90 & 0,95 \\
\hline \multirow[t]{5}{*}{4} & $2 / 2$ UD & $\mathrm{VL}$ & 0,94 & 0,96 & 0,99 & 1,01 \\
\hline & Atau jalan & $\mathrm{L}$ & 0,92 & 0,94 & 0,97 & 1,00 \\
\hline & satu arah & M & 0,89 & 0,92 & 0,95 & 0,98 \\
\hline & & $\mathrm{H}$ & 0,82 & 0,86 & 0,90 & 0,95 \\
\hline & & $\mathrm{VH}$ & 0,73 & 0,79 & 0,85 & 0,91 \\
\hline
\end{tabular}

Sumber: Jalan Perkotaan, MKJI 1997;5-53 
Tabel 2.6: Penyesuaian Kapasitas untuk Hambatan Samping (FCsf) berdasarkan Jarak Antara Kereb dan Penghalang pada Trotoar

\begin{tabular}{|c|c|c|c|c|c|c|}
\hline \multirow{3}{*}{ No } & \multirow{3}{*}{ Tipe Jalan } & \multirow{3}{*}{$\begin{array}{c}\text { Kelas } \\
\text { hambatan } \\
\text { samping }\end{array}$} & \multicolumn{4}{|c|}{$\begin{array}{l}\text { Faktor penyesuaian untuk hambatan samping dan lebar } \\
\text { bahuFCsf }\end{array}$} \\
\hline & & & \multicolumn{4}{|c|}{ LebarbahuefektifWs } \\
\hline & & & $\leq 0,5$ & 1,0 & 1,5 & $\geq 2,0$ \\
\hline \multirow[t]{5}{*}{1} & $4 / 2 \mathrm{D}$ & VL & 0,95 & 0,97 & 0,99 & 1,01 \\
\hline & & $\mathrm{L}$ & 0,94 & 0,96 & 0,98 & 1,00 \\
\hline & & M & 0,91 & 0,93 & 0,95 & 0,98 \\
\hline & & $\mathrm{H}$ & 0,86 & 0,89 & 0,92 & 0,95 \\
\hline & & $\mathrm{VH}$ & 0,81 & 0,85 & 0,88 & 0,92 \\
\hline \multirow[t]{5}{*}{2} & $4 / 2 \mathrm{UD}$ & VL & 0,95 & 0,97 & 0,99 & 1,01 \\
\hline & & $\mathrm{L}$ & 0,93 & 0,95 & 0,97 & 1,00 \\
\hline & & M & 0,90 & 0,92 & 0,95 & 0,97 \\
\hline & & $\mathrm{H}$ & 0,84 & 0,87 & 0,90 & 0,93 \\
\hline & & VH & 0,77 & 0,81 & 0,85 & 0,90 \\
\hline \multirow[t]{5}{*}{4} & $2 / 2 \mathrm{UD}$ & VL & 0,93 & 0,95 & 0,97 & 0,99 \\
\hline & Atau jalan & $\mathrm{L}$ & 0,90 & 0,92 & 0,95 & 0,97 \\
\hline & satu arah & M & 0,86 & 0,88 & 0,91 & 0,94 \\
\hline & & $\mathrm{H}$ & 0,78 & 0,81 & 0,84 & 0,88 \\
\hline & & VH & 0,68 & 0,72 & 0,77 & 0,82 \\
\hline
\end{tabular}

Sumber: Jalan Perkotaan, MKJI 1997;5-54

Tabel 2.7: Penyesuaian Kapasitas untuk Ukuran Kota (FCcs)

\begin{tabular}{cc}
\hline Ukuran kota (Juta penduduk) & Faktor penyesuaian untuk ukuran kota \\
\hline$<0,1$ & 0,86 \\
$0,1-0,5$ & 0,90 \\
$0,5-1,0$ & 0,94 \\
$1,0-3,0$ & 1,00 \\
$>3,0$ & 1,04 \\
\hline
\end{tabular}

Sumber: Jalan Perkotaan, MKJI 1997;5-55

Derajat kejenuhan (DS) didefenisikan sebagai rasio arus lalu lintas terhadap kapasitas, yang digunakan sebagai faktor utama dalam penentuan tingkat kinerja simpang dan segmen jalan. Nilai DS menunjukkan apakah segmen jalan tersebut mempunyai masalah kapasitas atau tidak. Untuk menghitung derajat kejenuhan pada suatu ruas jalan perkotaan dengan rumus (MKJI 1997) sebagai berikut :

$$
\mathrm{DS}=\mathrm{Q} / \mathrm{C}
$$

dimana :

DS $=$ Derajat kejenuhan

$\mathrm{Q}=$ Arus maksimum (smp/jam)

$\mathrm{C}=$ Kapasitas (smp/jam)

Dalam hal analisa perencanaan dan operasional persimpangan, disarankan untuk rasio arus/kapasitas tidak melewati nilai 0,75 selama jam puncak tahun rencana. 


\section{METODOLOGI}

\section{Lokasi Penelitian}

Penelitian dilakukan pada lokasi di ruas jalan . Lokasi penelitian dapat dilihat pada Gambar 3.1.

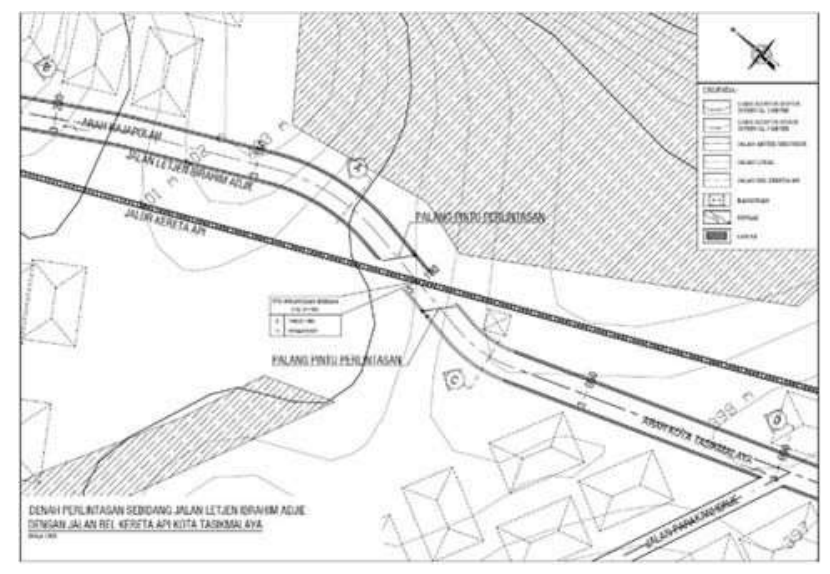

Sumber: Digital Elevation Model (DEM) dan Batimetri Nasional

Gambar 3.1: Denah Lokasi Perlintasan Sebidang Rel Kereta Api dengan Jalan Letjen Ibrahim Adjie Kota Tasikmalaya

\section{Metoda Penelitian}

Studi kasus ini dimulai dengan penjelasan mengenai fenomena dalam latar belakang dibuatnya studi kasus ini. Kemudian dirumuskan permasalahan yang terjadi saat ini dan ditetapkan tujuan studi kasus. Setelah itu direncanakan metodologi studi kasus dengan ditetapkan alur studi kasus dan langkah-langkah untuk memperoleh data yang diperlukan dalam analisis data. Adapun metode penyusunannya sebagai berikut :

a. Melakukan peninjauan dan identifikasi masalah pada perlintasan sebidang Jalan Letjen Ibrahim Adjie dengan Rel Kereta Api.

b. Mengumpulkan data primer dan data sekunder yang berhubungan dengan lokasi yang ditinjau untuk bahan evaluasi dan analisa.

c. Data primer didapat dengan melakukan survei langsung pada lokasi yang menjadi tinjauan studi kasus dengan cara mengukur, mengambil gambar dengan kamera digital, dan pendataan selama 24 jam selama 2 hari.

d. Data sekunder didapat dengan melakukan kunjungan ke dinas atau instansi terkait, dan mengklarifikasi data sesuai dengan data yang dibutuhkan.

e. Melakukan evaluasi volume lalu lintas jalan Letjen Ibrahim Adjie di perlintasan sebidang dengan Rel Kereta Api.

Untuk lebih jelasnya ruang lingkup pembahasan seperti Bagan Alir Gambar 3.2 sebagai berikut : 


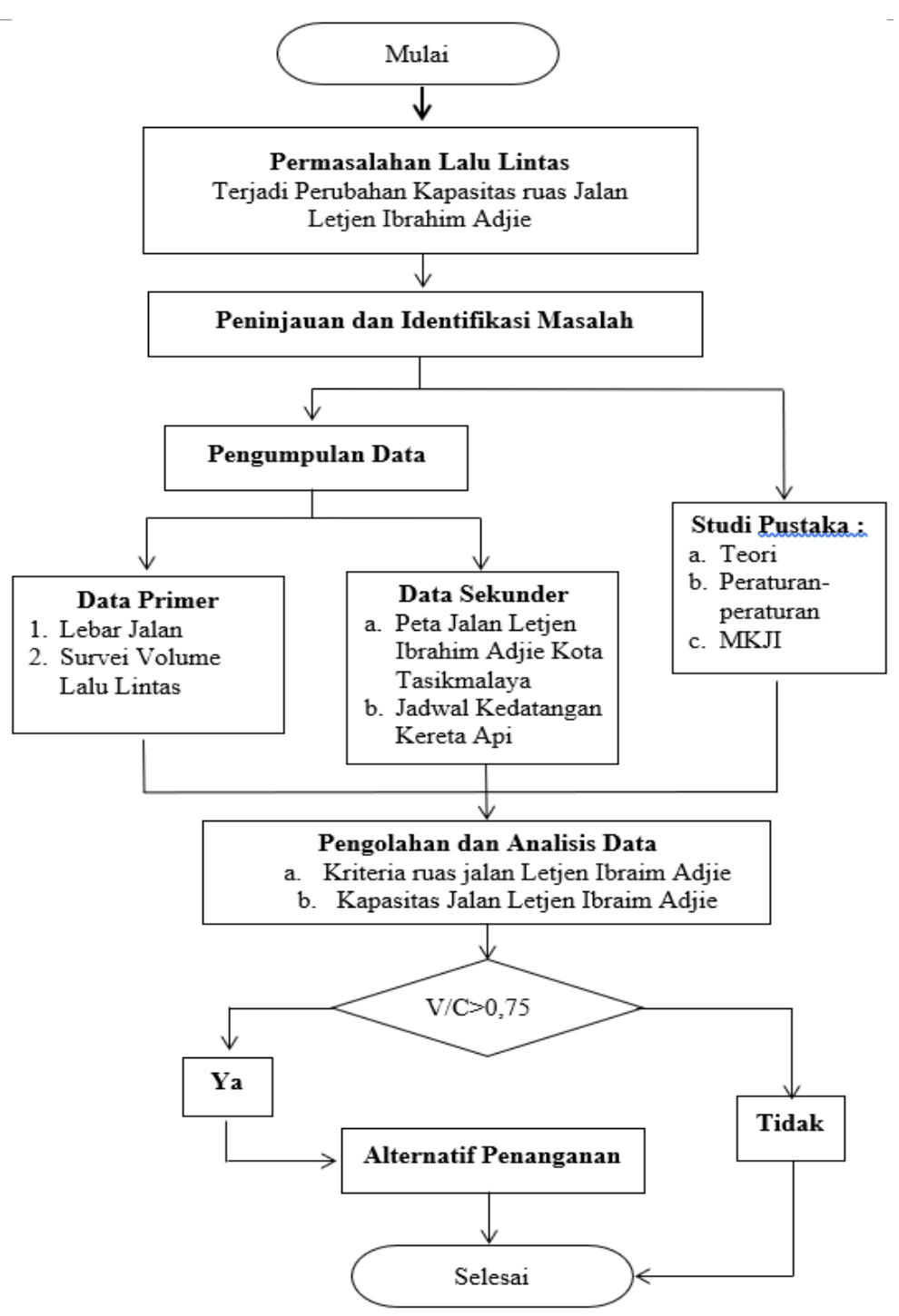

Gambar 3.2: Bagan Alir

\section{Metode Pengumpulan Data}

Cara pengumpulan data tersebut dapat dipisahkan menjadi 3 (tiga) pokok kegiatan antara lain sebagai berikut:

a. Data yang diperlukan

Data yang diperlukan tentunya harus sesuai dengan peninjauan terdahulu atau hasil identifikasi permasalahan.

b. Pengumpulan data

Data yang dikumpulkan adalah data primer dan data sekunder.

c. Pelaksanaan Survei

Data Primer didapatkan dengan pelaksanaan Survei langsung kelapangan, yaitu melalui Survei pengamatan, pengukuran, dan pendataan.

Data Sekunder didapatkan dengan mendatangi langsung kantor/instansi terkait sesuai dengan kebutuhan 


\section{ANALISIS DAN PEMBAHASAN}

\section{Pengolahan Data}

Berdasarkan formulir lapangan untuk ruas jalan (normatif) didapat data survei lapangan berupa jumlah volume kendaraan yang melewati titik pengamatan yang telah ditentukan berada di perlintasan sebidang STA 3+100 ruas jalan Letjen Ibrahim Adjie. Jumlah kendaraan yang dicatat sesuai dengan golongan kendaraan yang tertera pada formulir dengan delapan golongan kendaraan.

Pencatatan dilakukan dua hari, yaitu pada hari minggu dan senin selama 24 jam mulai pukul 00.00 s.d. 23.00 setiap 60 menit, jumlah kendaraan dihitung pada dua arah lalu lintas yaitu arah ke kota Tasikmalaya dan arah ke Rajapolah.

Adapun untuk jadwal penutupan palang pintu kereta api di perlintasan sebidang ruas jalan Letjen Ibrahim Adjie STA. 3+100 ditampilkan pada tabel 4.1 dibawah ini:

Tabel 4.1: Jadwal Penutupan Palang Pintu Kereta Api

\begin{tabular}{ccc}
\hline No. Sampel & Nama Kereta Api & Jam Melintas \\
\hline 1. & Mutiara & 06.27 \\
2. & Pasundan & 08.03 \\
3. & Lodaya & 09.57 \\
4. & Serayu & 10.20 \\
5. & Argowilis & 11.00 \\
6. & Lodaya & 13.15 \\
7. & Kutojaya & 13.55 \\
8. & Serayu & 15.14 \\
9. & Argowilis & 16.28 \\
10. & Mutiara & 18.31 \\
11. & Malabar & 19.39 \\
12. & Pasundan & 20.11 \\
\hline Sumber: PJL 337 Parakan honje Kota Tasikmalaya
\end{tabular}

Pengolahan data hasil survei kapasitas ruas jalan Letjen Ibrahim Adjie, dimaksudkan untuk menghitung jumlah kendaraan dua arah lalu lintas (kombinasi) berdasarkan golongan kendaraan sebagaimana yang tertera dalam formulir lapangan untuk ruas jalan normatif.

Tabel jumlah kendaraan hanya menunjukan jumlah terbanyak golongan kendaraan (kendaraan/jam) pada saat jam sibuk (pek hour) saja, yaitu pada pukul 16.00 sampai dengan pukul 17.00 di hari senin dan minggu. Di bawah ini ialah tabel jumlah golongan kendaraan:

Tabel 4.2: Jumlah Golongan Kendaraan (Kendaraan/Jam)

\begin{tabular}{|c|c|c|c|}
\hline & \multirow[b]{2}{*}{ Golongan Kendaraan } & \multicolumn{2}{|c|}{$\begin{array}{c}\text { Jumlah Golongan Kendaraan (Kend/Jam) } \\
\text { Saat (Peak Hour) }\end{array}$} \\
\hline & & $\begin{array}{c}\text { Hari Senin } \\
\text { Pukul } 16.00 \text { s.d. } \\
17.00\end{array}$ & $\begin{array}{c}\text { Hari Minggu } \\
\text { Pukul } 16.00 \text { s.d. } \\
17.00\end{array}$ \\
\hline 1 & Sepeda Motor & 1065 & 604 \\
\hline 2 & Sedan/Jeep/Station wagon & 109 & 98 \\
\hline 3 & $\begin{array}{l}\text { Opelet/Pick up opelet/Suburban, combi, } \\
\& \text { mini bus }\end{array}$ & 131 & 75 \\
\hline
\end{tabular}




\begin{tabular}{clcc}
4 & Pick up, micro truck, dan mobil hantaran & 72 & 25 \\
5a & Bus Kecil & 23 & 19 \\
5b & Bus Besar & 17 & 21 \\
6a & Truck Ringan 2 Sumbu & 24 & 34 \\
6b & Truck Sedang 2 Sumbu & 15 & 11 \\
$7 \mathrm{a}$ & Truck 3 Sumbu & 12 & 15 \\
7b & Truck Gandeng & 5 & 0 \\
7c & Truck Semi Trailer & 3 & 2 \\
8 & Kendaraan tidak bermotor & 0 & 0 \\
\hline
\end{tabular}

Sumber: Hasil survei volume kendaraan

\section{Analisis Data dan Pembahasan}

Analisa yang dilakukan adalah menghitung kebutuhan kapasitas ruas jalan Letjen Ibrahim Adjie, dengan cara menghitung rasio arus terhadap kapasitas.Permaszaan yang digunakan dalam perhitungan terdapat pada Persamaan 2.

$$
\mathrm{DS}=\mathrm{Q} / \mathrm{C}
$$

Dengan,

DS = Derajat kejenuhan

$\mathrm{Q}=$ Arus maksimum (smp/jam)

$\mathrm{C}=$ Kapasitas (smp/jam)

Arus maksimum didapat dari jumlah golongan kendaraan yaitu sebesar 997.74 (SMP/Jam), Sementara untuk kapasitas didapat dari persamaan:

Dengan,

$$
\mathrm{C}=\mathrm{Co} \times \mathrm{FCw} \times \text { FCsp } \times \text { FCsf } \times \text { FCcs }
$$

Co ialah kapasitas ruas jalan perkotaan (datar) sebesar 2900 (SMP/Jam)

$\mathrm{FCw}$ ialah faktor penyesuaian kapasitas untuk pengaruh lebar jalur lalu lintas untuk jalan perkotaan sebesar 1,29

FCsp ialah faktor penyesuaian kapasitas untuk pemisahan arah sebesar 1,00

FCsf ialah faktor penyesuaian kapasitas untuk hambatan samping berdasarkan lebar bahu efektif ws, sebesar 0,97

FCcs ialah penyesuaian kapasitas untuk ukuran kota sebesar 0,86 dengan jumlah penduduk mengacu pada data statistik Kota Tasikmalaya tahun 2019.

Maka didapat:

$$
\begin{aligned}
\mathrm{C} & =2900 \times 1,29 \times 1,00 \times 0,97 \times 0,86 \\
& =3120,7422
\end{aligned}
$$

Dengan demikian nilai rasio adalah :

$$
\text { 무 } \square \frac{997,74}{3120,7422} \square 0,3197 \text { 回 } 0,75
$$


Tabel 4.3: Analisa Kebutuhan Kapasitas

\begin{tabular}{|c|c|c|c|c|c|c|c|c|c|c|c|}
\hline \multirow[b]{2}{*}{ No. } & \multirow[b]{2}{*}{ Jenis Kendaraan } & \multirow{2}{*}{$\begin{array}{c}\mathrm{Q} \\
\frac{\text { SMP/Jam }}{2019} \\
\end{array}$} & \multirow[b]{2}{*}{ i ke-1 } & LHR & LHR & LHR & \multirow[b]{2}{*}{ i ke-2 } & \multirow{2}{*}{$\begin{array}{l}\text { LHR } \\
2031\end{array}$} & \multirow{2}{*}{$\begin{array}{c}\text { LHv R } \\
2032\end{array}$} & \multirow{2}{*}{$\begin{array}{l}\text { LHR } \\
2033\end{array}$} & \multirow{2}{*}{$\begin{array}{l}\text { LHR } \\
2034\end{array}$} \\
\hline & & & & 2020 & 2021 & 2022 & & & & & \\
\hline & & & Tahun ke - & 1 & 2 & 3 & Tahun ke - & 12 & 13 & 14 & 15 \\
\hline 1 & Sepeda Motor & 426.00 & $7.30 \%$ & 457.084 & 490.436 & 526.221 & $6 \%$ & 889.040 & 942.382 & 998.925 & $1,058.860$ \\
\hline 2 & Sedan/Jeep/Station wagon & 109.20 & $7.30 \%$ & 117.168 & 125.717 & 134.890 & $6 \%$ & 227.895 & 241.568 & 256.062 & 271.426 \\
\hline 3 & $\begin{array}{l}\text { Opelet/Pick up opelet/ } \\
\text { Suburban, } \\
\text { combi, \& mini bus }\end{array}$ & 170.35 & $7.30 \%$ & 182.782 & 196.119 & 210.429 & $6 \%$ & 355.516 & 376.847 & 399.457 & 423.425 \\
\hline 4 & $\begin{array}{l}\text { Pick up, micro truck, dan } \\
\text { mobil hantaran }\end{array}$ & 93.29 & $7.30 \%$ & 100.095 & 107.399 & 115.235 & $6 \%$ & 194.687 & 206.368 & 218.750 & 231.875 \\
\hline & Bus Kecil & 29.25 & $7.30 \%$ & 31.384 & 33.674 & 36.131 & $6 \%$ & 61.043 & 64.706 & 68.588 & 72.703 \\
\hline & Bus Besar & 21.45 & $7.30 \%$ & 23.015 & 24.694 & 26.496 & $6 \%$ & 44.765 & 47.451 & 50.298 & 53.316 \\
\hline & Truck Ringa & 31.20 & $7.30 \%$ & 33.477 & 35.919 & 38.540 & $6 \%$ & 65.113 & 69.020 & 73.161 & 77.550 \\
\hline & Truck Sedang 2 Sumbu & 19.50 & $7.30 \%$ & 20.923 & 22.450 & 24.088 & $6 \%$ & 40.695 & 43.137 & 45.725 & 48.469 \\
\hline & Truck 3 Sumbu & 60.00 & $7.30 \%$ & 64.378 & 69.075 & 74.116 & $6 \%$ & 125.217 & 132.730 & 140.694 & 149.135 \\
\hline & Truck Gandeng & 22.50 & $7.30 \%$ & 24.142 & 25.903 & 27.793 & $6 \%$ & 46.956 & 49.774 & 52.760 & 55.926 \\
\hline & Truck Semi Trailer & 15.00 & $7.30 \%$ & 16.095 & 17.269 & 18.529 & $6 \%$ & 31.304 & 33.182 & 35.173 & 37.284 \\
\hline & Kendaraan tidak bermotor & 0.00 & $7.30 \%$ & 0.000 & 0.000 & 0.000 & $6 \%$ & 0.000 & 0.000 & 0.000 & 0.000 \\
\hline Vol & ume & 997.74 & & $1,070.542$ & $1,148.656$ & $1,232.469$ & $6 \%$ & $2,082.231$ & $2,207.165$ & $2,339.595$ & $2,479.970$ \\
\hline \multicolumn{12}{|c|}{ KapasitasJalan2jalur $(\mathrm{SMP} / \mathrm{Jam})=\mathrm{COxFcwxFCspxFCsfxFCcs=3120.7422}$} \\
\hline \multirow{2}{*}{\multicolumn{2}{|c|}{ DS (Derajat Kejenuhan) }} & 0.3197 & & 0.343 & 0.368 & 0.395 & & 0.667 & 0.707 & 0.750 & 0.795 \\
\hline & & $\mathbf{L}$ & & $\mathbf{L}$ & $\mathbf{L}$ & $\mathbf{L}$ & & \multicolumn{3}{|c|}{ KL=Kurang Lancar } & M \\
\hline
\end{tabular}

Sumber: Hasil perhitungan, 2019 


\section{KESIMPULAN}

Dari hasil pengolahan data lapangan dan analisis yang telah dilakukan, maka kesimpulannya adalah sebagai berikut:

1. Penyusunan tugas akhir ini benar-benar merujuk pada peraturan dan kondisi lapangan yang terkait dengan kapasitas lalu lintas yang berada di kota tasikmalaya, studi kasus STA 3+000 ruas Jalan Letjen Ibrahim Adjie.

2. Hasil survei kriteria ruas Jalan Letjen Ibrahim Adjie, untuk STA 3+000 memiliki lebar jalan 10,6 m, STA 3+075 lebar jalan 9m, STA 3+125 lebar jalan 9,6 m, dan STA 3+200 lebar jalan 10,2 $\mathrm{m}$. Sementara fungsi jalan termasuk sistem jaringan jalan arteri sekunder yang seharusnya mempunyai lebar jalan minimal $11 \mathrm{~m}$.

3. Tingkat pelayanan ruas Jalan Letjen Ibrahim Adjie yang diamati pada kondisi geometrik jalan eksisting tahun 2019 dalam kondisi lalu lintas lancar atau $\mathrm{Q} / \mathrm{C}=$ $0,319<0,75$.

4. Menyikapi pertumbuhan kendaraan di kota Tasikmalaya 6\% per tahun maka, diperkirakan kondisi ruas jalan Letjen Ibrahim Adjie untuk tahun 2034 dengan tidak adanya perubahan kondisi geometrik, tingkat pelayanan jalan menjadi macet atau $\mathrm{Q} / \mathrm{C}=0,795>0,75$.

5. Sebagai bahan pertimbangan untuk alternatif penyelesaian masalah kemacetan maka perlu ada peningkatan pelayanan kapasitas jalan dengan dibuat perlintasan tidak sebidang, seperti fly over atau under pass.

\section{DAFTAR PUSTAKA}

Badan Pusat Statistik Kota Tasikmalaya. (2019). Statistik Daerah Kota Tasikmalaya.

CV. Bachtiar. Tasikmalaya.

Budi Hartanto Susilo. (2015). Rekayasa Lalu Lintas. Universitas Trisakti. Jakarta.

Clarkson H, Oglesby. (1999). Teknik Jalan Raya, Jilid 1. Alih Bahasa : Purwo Setianto. Jakarta. Gramedia.

Departemen Permukiman dan Prasarana Wilayah. (2004). Survei Pencacahan Lalu Lintas dengan Cara Manual. Jakarta.

Direktorat Jenderal Perhubungan Darat Tahun. (2005). Tentang Pedoman Teknis Perlintasan Sebidang Antara Jalan Dengan Jalur Kereta Api. Departemen Perhubungan Darat. Jakarta.

Dirjen Bina Marga. (1997). Manual Kapasitas Jalan Indonesia (1997). Bandung.

Direktorat Bina Marga. (1992). Tentang Standar Geometrik Perkotaan. Jakarta.

Id.wikipedia.org/wiki/Identifikasi.

Direktorat Jenderal Bina Marga Kementerian Pekerjaan Umum. (2013). Manual Desain Perkerasan Jalan. Jakarta.

Lucky Amperawan Schipper, ST., MT. (2018). Pedoman Pelaksanaan KP dan TA

Program Studi Teknik Sipil FTPA UNWIM Tahun 2018. Bandung.

Morlok, E. K. (1998). Pengantar Teknik Dan Perencanaan Transportasi

(Terjemahan) Erlangga. Jakarta.

Menteri Pekerjaan Umum dan Perumahan Rakyat. (2015). Keputusan Menteri Pekerjaan Umum dan Perumahan Rakyat Republik Indonesia Nomor: 250/KPTS/M/2015. Jakarta. 
Pemerintah Republik Indonesia. (1985). Undang-Undang Republik Indonesia Nomor 26 Tahun 1985 Tentang Jalan. Jakarta.

Pemerintah Republik Indonesia. (2004). Undang-Undang Republik Indonesia Nomor 38 Tahun 2004 Tentang Jalan. Jakarta.

Pemerintah Republik Indonesia. (2006). Undang-Undang Republik Indonesia Nomor 34 Tahun 2006 Tentang Jalan. Jakarta.

Peraturan Daerah Walikotamadya Tasikmalaya. (2012). Tentang Rencana Tata Ruang Wilayah. Tasikmalaya.

Salter, R.J. (1996). Highway Traffic Analysis and Design. 3rd ed. MacMilan Press, London.

Tim Penyusun Kamus Pusat Pembinaan dan Pengembangan Bahasa. (2003). Kamus Besar Bahasa Indonesia. Jakarta. Balai Pustaka.

Warpani, S. (1985). Rekayasa Lalu Lintas. Bhratara Aksara. Jakarta. 